DigitALCOMMONS @WAYNESTATE -
Michigan Journal of Counseling:

Research, Theory and Practice

Volume 36 | Issue 2

Article 4

9-1-2009

\title{
The Effects of Sexual Assault on the Identity Development of Black College Women
}

Wilma J. Henry

University of South Florida, whenry@usf.edu

Follow this and additional works at: https://digitalcommons.wayne.edu/mijoc

\section{Recommended Citation}

Henry, W. J. (2009). The Effects of Sexual Assault on the Identity Development of Black College Women, Michigan Journal of Counseling, 36(2), 17-23. doi:10.22237/mijoc/1251763380

This Article is brought to you for free and open access by the Open Access Journals at DigitalCommons@WayneState. It has been accepted for inclusion in Michigan Journal of Counseling: Research, Theory and Practice by an authorized editor of DigitalCommons@WayneState. 


\section{The Effects of Sexual Assault on the Identity Development of Black College Women}

\section{Wilma J. Henry, Ed.D. \\ University of South Florida}

Contact the author at:

4202 East Fowler Ave, EDU 162

Tampa, FL $33620-5650$

(813) $974-2430$

(813) 974-5814 (fax)

henry@coedu.usf.edu

Sexual assault victims face more social criticism than victims of any other crime. It is uncertain whether women of color are more at risk for sexual assault than White women during their college years. However, studies suggest that Black female sexual assault victims are more likely than White female victims to be blamed for their attacks and have their reports invalidated in the courts and on college campuses (Donovan, 2007; George \& Martinez, 2002). In this article identity development models are used to frame the intersecting effects of race and gender on the psychosocial wellbeing of Black female sexual assault victims in college. Implications for counseling and student affairs practice, as well as recommendations for future research are offered.

Key Words: sexual assault, Black college women, undergraduate, vulnerability, selfidentity olleges and universities remain settings where women are particularly at risk for experiencing all forms of unwanted sexual activity, namely, sexual assault (Cass, 2007). While there are different types of sexual assault - acquaintance rape, date rape, stranger rape, party rape, and gang rape, most rape occurs with individuals who have had some form of association or contact with the perpetrator prior to the incident of assault (Armstrong, Hamilton, Sweeney, 2006; Morway, 2006). Research indicates that there are factors influencing the risks for sexual assault among college women (Cass). Close quarters in residence halls, as well as the social interaction created from involvement in student organizations, such as Greek life, may further contribute to sexual pressure, which has been referred to as "a common element of college life" (Adams-Curtis \& Forbes, 2004, p. 94). Young college-aged women may also find themselves at a greater risk for sexual assault than older or married female college students given the fact the former group is typically single, often new to the university environment and adjusting to college life (Fisher, Daigle, Cullen \& Turner, 2003).

It is uncertain whether women of color are more or less vulnerable than White women to experiencing sexual assault during their college years (Cass; Fisher et al.; Gross, Winslett, Roberts, \& Gohm, 2006). It is clear however, that a void exists in the literature regarding sexual assault incidents suffered by Black women as a specific population (Long, Ullman, Starzynski, Long, \& Mason, 2007; West \& Rose, 2000). According to a longitudinal study of a mostly White survey sample by Smith, White, and Holland (2003), 88\% of women were sexually assaulted at one point from early adolescence through the end of college. Most sexual assault studies focus on White women and most rape incidents are intraracial (George \& Martinez, 2002; West \& Rose, 2000). Consequently, the effects of sexual assault on the identity development of Black female victims in the general population, as well as those in college, are largely unknown.

The compounding and devastating effects of racism, sexism, and sexual assault, which Black female rape victims encounter, are particularly damaging to their identity development. The purpose of this article is to explore the psychosocial effects of sexual assault and its impact on the identity development of Black 
college women. Helms' (1990) Womanist Identity Development theory and Cross' (1978) Black Racial Identity Development theory are used as the theoretical framework in contextualizing the influence of race and gender on the formation of self-identity among Black victims of sexual abuse.

\section{Theoretical Framework}

Cross' (1978) Black Racial Identity Development model illuminates the process by which Black women progress from a stereotypical, externally based identity to an internally based racial identity. In other words, Blacks move through a series of stages whereby they increasingly understand and positively embrace their race. The individual begins in the Pre-encounter stage, in which she does not call racist attitudes into question, but instead accepts negative social stereotypes. The initial questioning occurs during Encounter, which is the second stage. The Immersion-Emersion stage initially marks the critical reevaluation of Eurocentrism and the strong preference for anything representative of Black culture. The later part of this stage (Emersion) is not as "reactionary" as the first part (Immersion), yet it maintains the strong appreciation of all that Black culture entails (Cross). Once Black women enter the Internalization stage they begin to interpret the world in a broader way; they embrace, rather than idealize their racial identity (Cross). During this final stage, reaching out to the Black community is actively valued along with embracing an appreciation for Black culture in the larger society (Boisnier, 2003).

One perspective that is particularly relevant when examining the identity development of Black women is Helms' (1990) Womanist Identity Development Theory. This model conceptualizes the process by which women, especially women of color, develop internally constructed ideals of self rather than accepting external definitions and influences (Moradi, 2005). Helms' theory holds unique significance for Black women (and other women of color) because it parallels Cross' (1978) Racial Identity Development theory and illuminates the process by which women come to recognize, question and reject societal definitions of what it means to be a woman (Moradi). In essence, as Black women progress through both the womanist and racial identity development processes, they are better able to embrace who they are as an individual in terms of their race and gender. Consequently, the ways in which Black females consider their race and gender will impact how they view themselves and the various social situations they encounter. The self-identity of Black women may be related to how they respond to victimization.

\section{Literature Review}

The following literature review focuses on the prevalence of sexual assault on college campuses, effects of sexual assault on women in general, the reasons women do not report sexual assault, and social reactions to the sexual assault of Black women. In addition, a discussion is included regarding Black female victims at the intersection of racism and sexism.

\section{Prevalence of Sexual Assault on Campus}

Research indicates that between 8 to $35 \%$ of college women are victims of sexual assault, with the majority of assault victims being between the ages of 16 and 24 (Fisher et al., 2003). This high-risk population of women is more vulnerable because they are young, dating, and involved in the campus party scene (Cass, 2007; Gross, Winslett, Roberts, \& Gohm, 2006; Fisher et al.). Gross et al. conducted a survey of 935 undergraduate women in their sophomore, junior, and senior years at a southeastern public university to explore the prevalence and types of sexual violence in college. Findings revealed that $84.4 \%$ of sexual victimizations occurred within the female victims' first four semesters. Women are most at risk for sexual assault during the early years of college and by acquaintances (Krebs, Lindquist, Warner, Fisher, \& Martin, 2007; Smith, White, \& Holland, 2003). In fact, $80 \%$ of sexual offenses in college are committed by fellow students (Cass). Romeo (2004) points out that college campuses remain risky settings for young women due to the prevalence of acquaintance rapists known to the victim through a variety of social contexts, such as dating partners, fellow residents and organizational members. The party culture, which is emphasized in some fraternity and sorority organizations on campus, accounts for an often cited relationship between Greek life and sexual assault (Armstrong, Hamilton, \& Sweeney, 2006). Additionally, the pervasive substance abuse on college campuses likely serves as an additional risk factor, particularly since acquaintance rapes often involves alcohol (Anderson, Simpson-Taylor, \& Hermann, 2004). It has been suggested, however, that alcohol is less present in instances of the sexual assault of Black female victims (Gross et al.).

Although the campus environment includes many risk factors for instances of sexual assault, campus 
statistics do not always reflect a large number of rape incidents. For example, according to a published brochure of rape incidents at a large, major research university in the south, only one rape was reported in 2004, two in 2005, and ten in 2006. Conversely, Krebs et al. (2007) conducted a web-based survey regarding the prevalence of sexual assault on university campuses in large public universities in the South and Mid-West. Participants in the survey were a randomly sampled group of 5,446 female and 1,375 male undergraduate students. Survey results indicated that approximately $13.7 \%$ of undergraduate women are sexually assaulted once they have entered college. Thus there appears to be some inconsistency between the number of college students who actually file police reports and the number of college students who disclose their assault in an anonymous survey.

\section{Effects of Sexual Assault on Women}

Women face a variety of psychological issues due to the traumatic experience of being sexually assaulted as well as the societal stigmatization and self-blame they face as victims. Sexual assault victims often develop negative views of themselves, and they frequently self-blame for their own victimization experience. In fact, Long et al. (2007) suggested that sexual assault victims often blame themselves, society in general, the offender, and fate. In a national study, Fisher et al. (2008) investigated the sexual assault experiences of 4,446 college women and found that self-blame occurred most often when victims were under the influence of alcohol at the time of the assault incident.

In addition to self-blame, assault victims may face many other consequences including post traumatic stress disorder (PTSD), depression, alcohol abuse, and unsafe sex practices (Cecil \& Matson, 2006; Frazier, Conlon, \& Glaser, 2001). Depression and PTSD have been listed among the psychological issues that most commonly follow the trauma of sexual assault (Frazier et al., 2001). Black women are cited as experiencing more PTSD than women of other races (Long et al., 2007). Victims with PTSD often face increased levels of anxiety as well as depression, which can negatively impact motivation and concentration. Furthermore, PTSD may include feelings of detachment as well as fear of events victims may associate with the assault (Hansell \& Damour, 2008). Unfortunately, the psychological impact of the sexual trauma may continue to impact the victim's behavior in future relationships, leading to practices of unsafe sex with a variety of sexual partners (Cecil \& Matson, 2006). As noted by Cecil and Matson, this type of behavior increases the likelihood that victims may contract sexually transmitted diseases (STDs). Thus, Black female sexual assault victims may be more at risk for contracting STDs not simply because of the victimization experience, but due to their sexual decisions afterward.

\section{Reasons Women Do Not Report Sexual Assault}

As women are likely to face some degree of social blame, many are unlikely to report sexual assault. In fact, FBI records indicate that only $37 \%$ of all sexual assault victims report rape (Morway, 2006). According to Karjane et al. (2002), many victims do not report sexual assault because they are concerned that they will face public humiliation while their case may not appear convincing in court. These victims' fears are reasonable as courtroom questioning of victims' prior sexual behavior is a fairly common practice (Bohmer \& Parrot, 1993). Additionally, Morway points out that sexual assault victim's names are not protected by law; therefore, the media is able to publish victims' personal information without legal ramification.

Education and income status may also impact the likelihood of victims' reporting their sexual assault. In conducting a survey of 495 sexually assaulted African American women, Long et al. (2007) found that educated women had more knowledge of ways to cope with the after experience of rape; therefore, they were more likely to tell someone about their assault. These findings are surprising especially in light of the fact that college women typically underreport (Fisher et al., 2003).

Unfortunately, Black women may be particularly fearful and less likely to report due to social biases concerning their race. For example, in a study by Donovan (2007) regarding college students' perceptions of Black and White rape victims, findings revealed that Black women were less likely to be trusted as genuine victims and were more likely to be blamed for their sexual assault. Additionally, George and Martinez suggested that Black women sexual assault victims "are less likely than White women to have a rape case come to trial and lead to a conviction" (George \& Martinez, 2002, p. 111). In essence, Black women as well as other minority women are less likely to report their sexual assault experiences regardless of whether the rapist is of the same race as the victim or not (Fisher et al.). 


\section{Social Reactions to the Sexual Assault of Black Women}

While victims of sexual assault face more social criticism than victims of any other crime, the literature indicates that Black women are often portrayed as promiscuous and in some way contributing to their sexual assault (George \& Martinez, 2002). Simmons (2006), an activist for Black women's social concerns, explored the impact of racism and sexism in the media and in the courtroom. Simmons concluded that in the pop culture and legal arenas, there is a damaging typecast of Black women as "unrapeable," a label which suggests their rape experiences do not constitute federal crimes.

Donovan (2007) reported that Black female victims more than White female victims, when raped by a White male, were viewed as more promiscuous by the White male participants in the study. It is likely that popularized stereotypes of Black women contribute to this racial view on college campuses inasmuch as the media still perpetuates the notion that Black women are "hypersexual". In a survey of 623 college women conducted by Carmody and Washington (2001) regarding rape myth acceptance, these authors indicated that little difference exists between Black and White college students' views concerning who is to blame for sexual assault incidents (i.e. the victim or the assailant).

Other research findings revealed that Black and White college students did exhibit social biases based on the race of the victim. While there are few studies that examine college students' perceptions about assault victims, in an earlier study Varelas and Foley (1998) investigated how 126 Black and White college students viewed specific scenarios of rape when the race of the victim and the perpetrator were disclosed in several different rape stories. Findings indicated that White college students were more likely to attribute some fault to a Black woman for being raped if she were sexually assaulted by a Black man, than to a White woman sexually assaulted by a Black man. Similarly, using a 2 (victim race) $\times 2$ (perpetrator race) $\times 2$ (participant sex) factorial between-groups MANCOVA, Donovan (2007) used results of five questionnaires related to perceptions of victims and perpetrators to survey college students' judgments of Black and White rape victims. Results showed a Black sexual assault victim to be less believable and more responsible for her assault than a White victim. According to Brown and Testa (2007), these types of stereotypical social reactions hinder the healing and recovery process for Black sexual assault victims.

\section{Black Female Victims at the Intersection of Racism and Sexism}

In a national study by the U.S. Department of Justice (2008), 93.6\% of sexual assault and rape cases reported were found to be intraracial (i.e. victims and perpetrators were of the same race) while only $16.7 \%$ reported were interracial (i.e. victims and perpetrators were of different races). Research also suggests that Black women are unlikely to report Black men (George \& Martinez; Simmons). For example, in Simmons' documentary on the rape experiences of Black women, one student recounted her sexual assault experience at a predominantly White college, in which there was an existing issue of racial tension between the police and Black college men. This victim hesitated to report her sexual assault from a Black man due to her leadership as Black Student Union President: "I had advocated for Black men in terms of the police harassment so I didn't want to say anything" (Simmons). In Simmons' documentary, feminist author and president of the National Women's Studies Association (NWSA) Guy-Sheftall explained how Black women fear that by reporting intraracial rape they commit a disservice to their race. Consequently, Donovan and Williams contended that Black female victims of sexual assault exist at an intersection of racism and sexism; this dilemma accounts for much of their hesitancy in deciding whether or not to report. While there are very few studies concerning both sexual assault and racial identity development, White, Strube, and Fischer (1998) purport that a Black woman's decision to report sexual assault may depend on her racial identity development status. For example, if Black women identify with Cross' (1978) Emersion stage, in which they begin resenting Eurocentrism and begin strongly identifying with their race, Black female victims may be more inclined to preserve Black unity rather than acknowledge their individual concerns. Helms' (1990) Womanist Identity Development theory indicates that Black women identify with the Internalization stage when they view themselves holistically embracing their race and gender. Black female sexual assault victims in the Internalization stage would therefore be more likely to report rape regardless of the perpetrator's race. Thus, how female victims socially and culturally identify impacts their stance on whether or not they feel compelled to report rape. 


\section{Discussion and Implications}

According to research, due to the prevalence of sexual assault on college campuses women are at an increased risk for victimization during their college years, which may lead to a host of psychosocial issues. While studies suggest (Krebs et al., 2007; Fisher et al., 2003; Smith et al., 2003) that there is a high incidence of rape among college students, campus police reports often do not substantiate this assertion. Due to the pervasive and negative social stigmas associated with sexual assault, many women are reluctant to report their sexual assault incidents (Simmons, 2006). This is particularly problematic among Black female victims in college because they already suffer from marginalization and discrimination, particularly on predominantly White campuses. Additionally, these young women carry the burden of protecting the image of Black male perpetrators as well as live with the fear of challenging White male assailants. Due to the fact that Black female victims labor under the dual oppressive forces of racism and sexism in society, their accounts are likely dismissed because they are stereotyped as sexually promiscuous and therefore deserving of rape (Donovan \& Williams, 2002).

One of the issues that Black female rape victims may face is overcoming the feeling that they are somehow to blame for their victimizations. Taken together, Cross (1978) Black Identity Development model and Helms? (1990) Womanist Identity Development model may be particularly useful in working with victims struggling to overcome self-blame. For example, Black college women, who conform to common societal stereotypes, and are in the Pre-encounter stage of Cross' and Helms' models of identity development, may likely blame themselves for their victimization (Boisnier et al., 2003). Conversely, a Black college woman who has come to reject negative societal definitions of blackness and womanhood may be better positioned to resist blame. In other words, the more inclined these women are to agree with social stereotypes about gender and race, the more likely they may be to find fault with themselves for becoming victims. Thus, college counselors should be aware of Cross' and Helms' models of identity development to ensure that their counseling strategies and techniques are developmentally and culturally relevant.

There is evidence that Black sexual assault victims are particularly vulnerable to PTSD (Long et al., 2007). Since a common symptom of PTSD is depression, these women may be less likely to engage in healthy behaviors, seek positive relationships, or look forward to their future. As suggested by Helms' (1990) model, Black women in the Immersion-Emersion stage of identity formation are particularly interested in developing close associations with other Black women. Thus, knowledge of this theory could provide useful cues in establishing group counseling opportunities in which Black female rape victims may be able to connect with other Black women who have had similar experiences (Henry \& Glenn, 2008). Thus, group counseling sessions may be an appropriate intervention for Black female victims as they may feel empowered by voicing their thoughts and may be able to establish a sense of camaraderie while sharing their experiences (Williams, Frame, \& Green, 1999), all of which can support healthy identity formation. These types of programs should be highlighted in counseling centers and campus support services marketing publications.

In addition to counseling services, student affairs professionals may assist Black female sexual assault victims achieve a healthy identity by offering programs and services that empower these women to regain control of their lives. One way that these women may seek to resist the effects of their victimization is to advocate on behalf of other victims of sexual assault. Campus programs may provide a platform to inspire these women to grow to a more mature stage of identity development and give voice to their new found activism. For example, student organizations such as Black student unions, sororities, as well as women's organizations, may provide venues in which these women can speak out against the sexual victimization of women on campus. Further, campus-wide multicultural and women's studies programs, campus activities boards, and residence hall programs can serve as curricular and co-curricular learning environments in which Black college women may be able to develop effective coping skills and understand behaviors that lead to mature identities (Henry, 2008) in spite of their victimization.

Due to the likelihood that many Black female rape victims do not report their assaults, do not seek formal mental health assistance, and may not participate in campus programs that deal with sexual victimization, it is important that these women have access to psychologists, and trained counselors as well as credentialed student affairs professionals who can provide appropriate support. Pope, Reynolds, 
and Mueller (2004) emphasize the importance of multicultural competence as essential to effective practice among student affairs professionals. It is important that student affairs professionals are aware of the compounding effects of racism, sexism, and rape on the identity development of Black female victims. Thus, they should have the cultural competency to both empathize with Black women victims, and the knowledge of identity development theory to assist these women in developing a healthy self-identity.

Further research, to include qualitative and quantitative studies, regarding Black sexual assault victims and identity development would be useful contributions to the literature. These studies should focus on identifying issues of Black female sexual assault victims as well as strategies that may assist these women to overcome the psychosocial, physical, and sociopolitical factors that damage their self-identity and self-sufficiency. In addition, further research may assist in policy changes that reflect the seriousness of rape, preventioneducation, and responses to sexual assault on campus. More recent college studies may indicate the need for greater cultural competency on the part of college administrators and counselors. While studies continue to focus on which prevention and empowerment strategies may be effective for college women in general (Jouriles, McDonald, Kullowatz, Gomez, \& Cuevas, in press), research may also indicate which strategies specifically address the needs of Black women.

\section{References}

Adams-Curtis, L. E., \& Forbes, G. B. (2004). College women's experiences of sexual coercion: A review of cultural, perpetrator, victim, and situational variables. Trauma, Violence, \& Abuse, 5(2), 91-122.

Anderson, V. N., Simpson-Taylor, D., \& Herrmann, D. J. (2004). Gender, age, and rape-supportive rules. Sex Roles, 50(1), $77-90$.

Armstrong, E. A., Hamilton, L., \& Sweeney, B. (2006). Sexual assault on campus: A multilevel, integrative approach to party rape. Social Problems, 53(4), 483-499.

Bohmer, C., \& Parrot, A. (1993). Sexual assault on campus: The problem and the solution. New York: Lexington Books.

Boisnier, A. (2003). Race and women's identity development: Distinguishing between feminism and womanism among black and white women. Sex Roles, 49(5-6), 211-218.

Brown \& Testa (2007). Social influences on judgments of rape victims: The role of the negative and positive social reactions of others. Sex Roles, 58, 490-500.

Carmody, D., \& Washington, L. (2001). Rape myth acceptance among college women: The impact of race and prior victimization. Journal of Interpersonal Violence, 16(5), 424.

Cass, A. I. (2007). Routine activities and sexual assault: An analysis of individual-and school-level factors. Violence and Victims, 22(3), 350-366.

Cecil, H., \& Matson, S. C. (2006). Sexual victimization among African American adolescent females: Examination of the reliability and validity of the sexual experiences survey. Journal of Interpersonal Violence, 21(1), 89-104.

Cross, W. E. (1978). The Thomas and Cross models of psychological nigrescence: A review. Journal of Black Psychology, $5(1), 13-31$.

Donovan, R., \& Williams, M. (2002). Living at the intersection: The effects of racism and sexism on black rape survivors. Women and Therapy, 25(3/4), 95-106.

Donovan, R. A. (2007). To blame or not to blame: Influences of target race and observer sex on rape blame attribution. Journal of Interpersonal Violence, 22(6), 722-736.

Fisher, B. S., Daigle, L. E., Cullen, F. T., \& Turner, M. G. (2003). Reporting sexual victimization to the police and others: Results from a national-level study of college women. Criminal Justice and Behavior, 30(1), 6-38. 


\section{References}

Frazier, P., Conlon, A., \& Glaser, T. (2001). Positive and negative life changes following sexual assault. Journal of Consulting and Clinical Psychology, 69(6), 1048-1055.

George, W. H., \& Martinez, L. J. (2002). Victim blaming in rape: effects of victim and perpetrator race, type of rape, and participant racism. Psychology of Women Quarterly, 26, 110-119.

Gross, A. M., Winslett, A., Roberts, M., \& Gohm, C. L. (2006). An examination of sexual violence against college women. Violence Against Women, 12(3), 288-300.

Hansell, J. \& Damour, L. (2008). Abnormal psychology. (2nd Ed). Hoboken, NJ: John Wiley \& Sons.

Helms, J. E. (1990). Black and white racial identity: Theory, research, and practice. New York: Greenwood Press.

Henry, W. J. (2008). Black female millennial college students: Dating dilemmas and identity development. Multicultural Education, 16(2), 17-21.

Henry, W. J., \& Glenn, N. M. (2008). Black women employed in the ivory tower: Connecting for success. Advancing Women in Leadership Journal, 25(1). Retrieved April 17, 2009, from http://advancingwomen.com/awl/awl_wordpress/ black-women-employed-in-the-ivory-tower-connecting-for-success-2/

Jouriles, E., McDonald, R., Kullowatz, A., Rosenfield, D., Gomez, G.,\& Cuevas, A. (in press). Can virtual reality increase the realism of role plays used to teach college women sexual coercion and rape-resistance skills? Behavior Therapy.

Krebs, C. P., Lindquist, C. H., Warner, T. D., Fisher, B. S., \& Martin, S. L. (2007, December) Campus sexual assault (CSA) study (Report\# NCJ 221153). Research Triangle Park, NC: RTI International. Retrieved April 19, 2009, from http://www. ncjrs.gov/pdffiles1/nij/grants/221153.pdf

Long, L. D. M., Ullman, S. E., Starzynski, L. L., Long, S. M., \& Mason, G. E. (2007). Age and educational differences in African American women's sexual assault experiences. Feminist Criminology, 2(2), 117-136.

Moradi, B. (2005). Advancing womanist identity development: Where we are and where we need to go. The Counseling Psychologist, 33(2), 225-253.

Morway, R. (2006). Date rape stories and media coverage. Retrieved December 4, 2008, from www.ibiblio.org

Pope, R. L., Reynolds, A. L., \& Mueller, J. A. (2004). Multicultural competence in student affairs. San Francisco: JosseyBass.

Romeo, F. (2004). Acquaintance rape on college and university campuses. College Student Journal, 38, 61-65.

Simmons, A. S. (Director). (2006). No! A documentary on rape. [Motion Picture]. Philadelphia: AfroLez Productions.

Smith, P., White, J., \& Holland, L. (2003). A longitudinal perspective on dating violence among adolescent and college-aged women. American Journal of Public Health, 93(7), 1104-1109.

U.S. Department of Justice. (2008). Criminal victimization in the United States, 2006 statistical tables. Retrieved August 27, 2009 from http://www.ojp.usdoj.gov/bjs/pub/pdf/cvus0602.pdf

Varelas, \& Foley, (1998). Blacks' and whites' perceptions of interracial and intraracial date rape. The Journal of Social Psychology, 138(3), 392-400.

West, C. M., \& Rose, S. (2000). Dating aggression among low income African American youth: An examination of gender differences and antagonistic beliefs. Violence Against Women, 6(5), 470-494.

White, A. M., Strube, M. J., \& Fisher, S. (1998). Implications for research and antirape advocacy in black communities. Psychology of Women Quarterly, 22(2), 157-175.

Williams, C., Frame, M., \& Green, E. (1999). Counseling groups for African American women: A focus on spirituality. The Journal for Specialists in Group Work, 24, 260-273. 